\title{
Gestão, Formalismos e Desenvolvimento de Software - Uma Análise Acerca Das Produções Brasileiras
}

\author{
Luiz Gustavo Dias ${ }^{1}$; Vaston Gonçalves da Costa ${ }^{2}$
}

\section{Resumo}

Gerenciamento de conhecimento voltado à Gestão de Habilidades emprega métodos específicos que visam aumentar a competitividade de empresas por meio das habilidades dos seus colaboradores. Em suma, trata o conhecimento existente de forma a que possam inferir informações úteis para o desenvolvimento de ações. Ao contrário de outros métodos, uma abordagem formal visa inferir informações consistentes do conhecimento. Metodologias que utilizam métodos formais e gestão do conhecimento são amplamente utilizadas ao redor do mundo, buscando produzir e promover melhor uso do conhecimento para as organizações através de ilações por meio da gerência em conhecimento prévio e skills por exemplo. Neste sentido este trabalho apresenta um estudo bibliográfico realizado acerca da produção científica disponibilizada por um periódico brasileiro focado em inovação, a fim de verificar se os temas gestão de habilidades, métodos formais e desenvolvimento de software estão sendo trabalhados em conjunto e o que está sendo produzido quanto a esses temas.

\section{Palavras Chave: -}

1 Mestrando em Gestão Organizacional, Universidade Federal de Goiás - Regional

Catalão (UFG/RC). Catalão - GO, Brasil.

2 Docente da Universidade Federal de Goiás - Regional Catalão (UFG/RC).

Catalão - GO, Brasil. 


\section{Introdução}

É indispensável que as empresas gerenciem o conhecimento utilizado em seus produtos e serviços de forma adequada para garantir aprendizado, crescimento e preservação do capital intelectual. Desta forma, técnicas de gerência aplicadas ao conhecimento são cada vez mais utilizadas no âmbito organizacional, garantindo dentre vários benefícios a competitividade perante o mercado.

Dentre técnicas e ferramentas que oferecem suporte à GC (gestão do conhecimento), pode-se citar a utilização de métodos formais, que utilizam princípios matemáticos para garantir a corretude e integridade nos processos de especificação desenvolvimento e validação de sistemas.

Como resultado da utilização de princípios formais em GC, pode-se citar a lógica de descrição (DL description logic) no desenvolvimento da chamada Web Semântica, onde enormes bases de conhecimento de origens diversas estarão disponíveis na rede para serem consultadas e manipuladas por agentes inteligentes.

Classificada como uma ferramenta da GC pode-se citar o uso de ontologia, que segundo Lukács (2015), tiveram origem da filosofia. Aplicadas à computação, ontologias podem ser entendidas como sistemas conceituais declarativos e relacionais. Um domínio representado por ontologia é construído por vocabulário, regras, e termos, que quando combinados, modelam o domínio e possibilita a inferência de conhecimento. Ao unir as informações definidas na estrutura ontológica, aplicar consultas por meio da DL por meio de um raciocinador, é possível inferir conhecimento ainda não definido (STAAB; STUDER, 2013).

O resultado satisfatório da união técnicas utilizadas para o desenvolvimento deste estudo, pode ser compreendido nos trabalhos de Colucci et. al. (2003) e no trabalho de Andrade, Ferreira e Pereira (2016), onde o primeiro trabalho documenta o desenvolvimento de um sistema baseado em metodologia formal cuja finalidade é realizar combinações entre candidatos a uma oportunidade de trabalho e vagas disponíveis, gerando resultados potenciais e parciais; e o segundo trabalho pode-se perceber a satisfatibilidade através de utilização de método formal aplicado à gestão do conhecimento, no processo de desenvolvimento do produto, tendo em vista que tal processo gera e manipula grande quantidade de informações e com a utilização de um método formal, tais informações podem ser organizadas, classificadas e representadas.

Embasado no exposto, esta pesquisa busca avaliar o que é produzido utilizando métodos formais aplicados à gestão do conhecimento em esfera nacional, tendo como diretório base, um periódico focado em pesquisas relacionadas ao desenvolvimento de inovações.

O trabalho e dividido em quatro seções onde a primeira é destinada à Introdução do que será abordado, a segunda seção é destinada à metodologia empregada para o desenvolvimento do trabalho, resultados e discussões são apresentados na seção três, e as conclusões acerca do trabalho são apresentadas na quarta e última seção.

\section{Desenvolvimento}

\subsection{Metodologia}

Este estudo possui abordagem qualitativa, uma vez que serão apresentados resultados de uma análise bibliográfica que visa emergir aspectos subjetivos relacionados a utilização de gestão do conhecimento e métodos formais (Dalfovo, 2008). A metodologia empregada para o desenvolvimento desta pesquisa é representada pela Figura 1. 


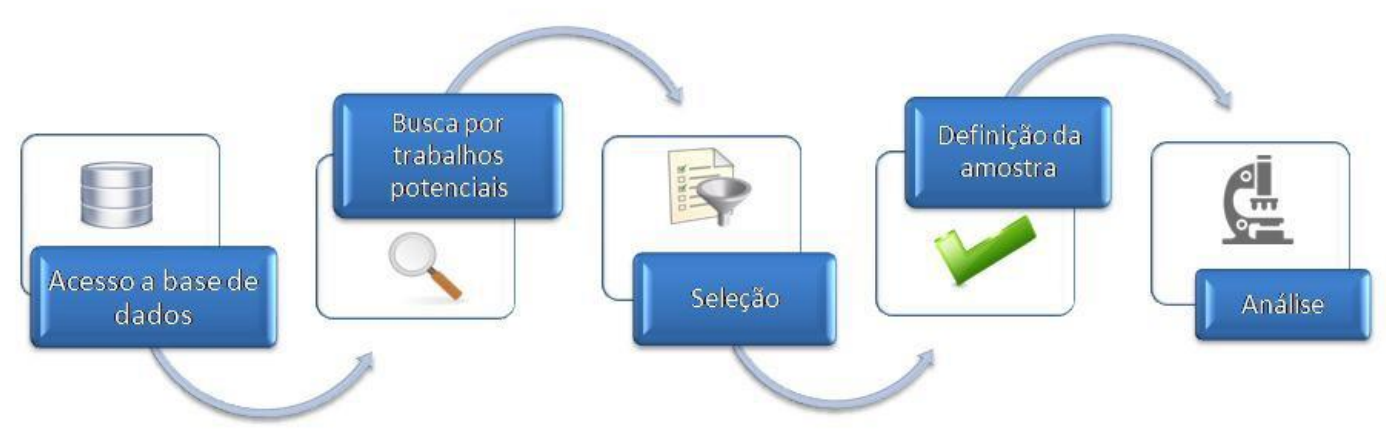

Fig.1, Representação dos passos metodológicos.

Como mostrado na Figura 1, para a realização deste trabalho foram seguidos quatro passos básicos para a definição da amostra e análise, que são descritos a seguir.

- Passo 1 - Acesso a base de dados: Para que fosse possível a realização do mesmo, foi necessária a aquisição de material bibliográfico que trabalhasse os temas "Desenvolvimento de Software", "Gestão do Conhecimento" e "Métodos Formais" no cenário brasileiro, para isso foi definido como diretório de pesquisa, a $\mathrm{RBI}^{3}$ (Revista Brasileira de Inovação), que possui perfil online. Tal revista foi definida levando em consideração seu escopo, pois possui perfil interdisciplinar com foco em estudos da inovação, apoiando o debate acadêmico acerca da inovação, avanços científicos e tecnológicos e seus impactos econômicos, sociais, organizacionais e ambientais que contribuem para a disseminação de novos conhecimentos e para a formulação de políticas públicas e gestão de organizações. Levando em consideração o perfil e credibilidade do diretório bibliográfico, podem-se citar como principais características motivadoras para sua utilização neste trabalho, a diversidade de material publicado e áreas de aplicação, que variam em diversos campos do conhecimento.

- Passo 2 - Busca por trabalhos potenciais: Como dito, o periódico escolhido para base de buscas tem como principal característica a divulgação de pesquisas interdisciplinares que abordam temas relacionados à inovação. Para que facilitar a seleção de trabalhos potenciais, as buscas foram filtradas de acordo com três perfis, sendo eles Gestão de Habilidades, Métodos Formais e Desenvolvimento de Software

- Passo 3 - Verificação do critério de seleção: a fim de buscar e analisar pesquisas que possuem perfil inovatório, foi definido como critério seleção da amostra: toda a publicação bibliográfica que fosse resultada da busca dos filtros definidos no passo 2, publicados nos últimos onze anos.

- Passo 4 - Definição da amostra: Após concluir os passos anteriores, a amostra foi definida.

- Passo 5 - Análise: A amostra selecionada para a realização deste estudo foi analisada seguindo três critérios: Nível de inovação proporcionado pelo estudo; Método formal utilizado para o desenvolvimento do estudo; Área de aplicação. Tais critérios foram definidos a fim de identificar a interdisciplinaridade, e a quão benéfica ela se torna em sua área de aplicação. Para fins de organização e 
${ }^{3}$ http://ocs.ige.unicamp.br/ojs/rbi 
verificação da evolução tecnológica, a análise dos trabalhos é foi feita por ordem cronológica.

\subsection{Resultados e Análise}

Esta seção é destinada à apresentação dos resultados, inicialmente são apresentadas as análises a respeito da idéia fundamental dos trabalhos e posteriormente é apresentada a análise.

O primeiro trabalho analisado é o trabalho de Freire e Brisolla (2004), intitulado "A Contribuição do Caráter "Transversal" do Software para a Política de Inovação". No estudo, os autores buscam mostrar características de software em empresas que trabalham com processos feitos de maneira praticamente artesanal, e destacam a real importância na inovação. Como argumento é citado o uso de software ERP (Enterprise Resource Planning) que são utilizados para integrar base de dados organizacionais que são enquadrados em diferentes ramos da empresa como contabilidade, gerenciamento de investimentos, controle de material, vendas e etc. Programas desse tipo visam a automação de serviços e geral uma visão global da "saúde organizacional", visto que é possível cruzar dados de diferentes áreas para traçar estratégias por exemplo.

Em contrapartida, os mesmos possuem preços elevados e interferem na estrutura organizacional. Um estudo de caso é realizado tendo como setor da construção civil como domínio, e dentre várias características que influenciam no processo de implantação de programas com perfil ERP são os diferentes perfis de fornecedores e inexistência de padrões para troca de informações. Para identificar atuações de empresas de software os autores realizam uma pesquisa através de questionário em 190 empresas do ramo da construção, com a finalidade de identificar as ferramentas ERP utilizadas pelas empresas, utilização de ferramentas específicas no domínio da construção, e aquisição de ferramentas desenvolvidas sob encomenda. Os autores concluem o estudo utilizando diversos argumentos, entre eles, a importância de ferramentas computacionais no ramo da construção, pois além de apoio administrativo, servem como ferramenta estratégica, mostrando seu caráter "transversal".

O segundo trabalho analisado, "Análise da Indústria Brasileira de Software com Base em uma Taxonomia das Empresas: Subsídios para a Política Industrial" - Roselino (2006) é mostrado o esforço da caracterização da indústria nacional de software, levando em conta os fatores envolvidos pelas atividades das empresas enquadradas no ramo de desenvolvimento e comércio de software. É elaborada uma taxonomia a partir de questionários desenvolvidos e aplicados na Pesquisa Anual de Serviço (PAS/IBGE). Através das análises realizadas pelo estudo, é notado que não apenas iniciativas voltadas às atividades puramente tecnológicas promovem o desenvolvimento da indústria de software, pois setores tradicionais heterogêneos também propiciam o desenvolvimento de empresas nacionais voltadas ao desenvolvimento de soluções computacionais. Outro ponto levantado com o estudo é a necessidade da política setorial se voltar para problemas nacionais, e não estimular a exportação e atuação das emrpresas brasileiras no cenário nacional.

A terceira pesquisa denominada "Processo Inovativo na Indústria de Software de Joinville (SC): uma análise a partir do marco teórico neo-schumpeteriano", (RAUEN; FURTADO; CÁRIO, 2009) busca explicitar e compreender a criação e difusão de inovações analisando a indústria de software no município de Joinville. Através de entrevistas, foi constatado que as empresas interagem pouco com os centros de pesquisa, as leis locais de incentivo ao setor são pouco conhecidas e o preço da mão de obra fundamenta a competitividade das empresas.

Por fim o quarto e último trabalho, intitulado "Uma conspiração multidimensional em torno da indústria de software: argumentos para a intervenção em setores de alta intensidade tecnológica" (Araújo; Sousa; Araújo 2010), debate a relação estado versus indústrias tecnológicas. Com o trabalho, os autores provam que diferente de empresas de outros ramos, a indústria de software é intensiva em trabalho e não em capital.

Como definido na seção dois, os trabalhos foram analisados seguindo três critérios: Se propõem software inovador; Se utiliza método formal; Área de aplicação. A análise é apresentada na Tabela 1. 
Tabela 1: Relação dos resultados obtidos na pesquisa Fonte: Os autores.

\begin{tabular}{cccc}
\hline Trabalho & Critério 1 & Critério 2 & Critério 3 \\
\hline Trabalho 1 & não & não & Administração \\
Trabalho 2 & não & não & $\begin{array}{c}\text { Pesquisa e } \\
\text { Desenvolvimento }\end{array}$ \\
Trabalho 3 & não & não & $\begin{array}{c}\text { Pesquisa e } \\
\text { Desenvolvimento } \\
\text { Trabalho 4 }\end{array}$ \\
& não & não & $\begin{array}{c}\text { Pesquisa e } \\
\text { Desenvolvimento }\end{array}$ \\
\cline { 3 - 4 }
\end{tabular}

Como visto na Tabela 1 , os trabalhos analisados neste estudo não fizeram uso dos tópicos definidos na seção metodológica. Apenas um trabalho abordou a importância do software e seu impacto quando utilizados efetivamente no ramo empresarial. Os outros trabalhos analisados trataram questões políticas sobre pesquisa e desenvolvimento e a influência do estado no processo de produção intelectual.

Sendo assim nota-se que as produções bibliográficas nacionais relacionadas à documentação de novas tecnologias de software aplicadas são pouco abordadas no periódico analisado. A abordagem se torna inexistente quando o desenvolvimento de software é relacionado a métodos formais e gestão do conhecimento/habilidades.

\section{CONSIDERAÇÕES FINAIS}

Como visto na seção introdutória neste trabalho, a utilização de metodologias voltadas à gerência do conhecimento, quando unidas à metodologias formais para a representação do conhecimento possibilita a criação de conhecimentos advindos de informações conhecias a priori. A vantagem da utilização destas duas técnicas no processo de idealização e criação de software resulta de forma direta ou indireta em inovação, seja no produto criado, ou mesmo na área de aplicação.

Como percebido neste trabalho, a produção científica que uni a representação do conhecimento e a criação de nossos produtos de software ainda são baixos no cenário nacional.

O periódico definido para a realização desta pesquisa teve como pontos de influencia, o perfil inovatório, onde acontece a interdisciplinaridade entre diferentes áreas do conhecimento. $O$ objetivo deste trabalho foi alcançado, visto que todos os trabalhos analisados se enquadraram nos requisitos definidos inicialmente, entretanto, foram analisados de acordo com a consulta realizada sobre o termo "Desenvolvimento de Software", pois as consultas realizadas à base de dados utilizando o termo "Gestão de Habilidades" e "Métodos Formais" não retornaram nenhum trabalho. 


\section{Management, Formalities and Software Development - An Analysis About The Brazilian scientific.}

\section{Abstract}

knowledge management focused on the Skills Management employs specific methods aimed at increasing the competitiveness of companies through the skills of its employees. To sum it up, deal the existing knowledge in a way that they infer useful infomation for the actions development. Unlike other methods, a formal approach aims to infer knowledge consistent information. Methodologies using formal methods and knowledge management are widely used around the world, seeking to produce and promote better use of knowledge through lessons by management in prior knowledge and skills for example. In this sense this paper presentes a bibliographic study of scientific studies provided by a Brazilian jornal focused on innovation in order to verify whether the skills of management issues, formal methods and software development are being worked together and what is being produced about there issues.

Keywords: Knowledge Management, Skills Management, Formal Methods.

\section{Referências}

ARAÚJO, Silvio Vanderlei; DE SOUSA, Alisson Santos; ARAÚJO, Emerson Wilian. Uma conspiração multidimensional em torno da indústria de software: argumentos para a intervenção em setores de alta intensidade tecnológica. Revista Brasileira de Inovação, v. 9, n. 2 jul/dez, p. 291-322, 2010.

COLUCCI, Simona et al. A formal approach to ontology-based semantic match of skills descriptions. J. UCS, v. 9, n. 12, p. 1437-1454, 2003. 
DALFOVO, Michael Samir; LANA, Rogério Adilson; SILVEIRA, Amélia. Métodos quantitativos e qualitativos: um resgate teórico. Revista Interdisciplinar Científica Aplicada, v. 2, n. 3, p. 1-13, 2008.

FREIRE, Emerson; DE NEGRAES BRISOLLA, Sandra. A contribuição do caráter "transversal" do software para a política de inovação. Revista Brasileira de Inovação, v. 4, n. 1 jan/jun, p. 97-128, 2009.

LUKÁCS, György. Para uma ontologia do ser social 1. Boitempo Editorial, 2015.

ROSELINO, José Eduardo. Análise da indústria brasileira de software com base em uma taxonomia das empresas: subsídios para a política industrial. Revista Brasileira de Inovação, v. 5, n. 1 jan/jun, p. 157-201, 2006. 
RAUEN, André Tortato; FURTADO, André Tosi; CÁRIO, Sílvio Antônio Ferraz. Processo Inovativo na Indústria de Software de Joinville (SC): uma análise a partir do marco teórico neo-schumpeteriano. Revista Brasileira de Inovação, v. 8, n. 2 jul/dez, p. 437-480, 2009.

STAAB, Steffen; STUDER, Rudi (Ed.). Handbook on ontologies. Springer Science \& Business Media, 2013. 